\title{
WALKING TRIP GENERATION AND BUILT ENVIRONMENT: A COMPARATIVE STUDY ON TRIP PURPOSES
}

\author{
Aryan Hosseinzadeh $^{1}$, Asiye Baghbani ${ }^{2}$ \\ ${ }^{1}$ Department of Civil and Environmental Engineering, University of Louisville, W.S. Speed, Louisville, KY, USA \\ ${ }^{2}$ Traffic Research Laboratory, School of Civil Engineering, Iran University of Science and Technology, Tehran, Iran
}

Received 28 April 2020; accepted 16 July 2020

\begin{abstract}
In recent decades, enhancing the share of walking in individuals' daily trips has become a priority for transportation policymakers, urban planners and public health researchers as an interdisciplinary area. In this regard, determining influential factors on walking has become a matter of contention to move toward a sustainable mode of transportation. This study investigates the impact of the influencing factors on the share of walking in trip generation from/to Traffic Analysis Zones (TAZ) of a city across four trip purposes. In this study, individuals' trip information for four trip purposes has been tested in order to detect influencing factors on walking trip generation based on 112 TAZs for the city of Rasht, Iran. According to the results, density and design are found to be more influential for produced walking trips and diversity is shown to be more effective for attracted walking trips.
\end{abstract}

Keywords: walking, built environment, trip generation, transportation network design, population density, land use diversity.

\section{Introduction}

Switching to walking as a non-motorized mode of transportation could significantly affect the transportation statuses of cities (Ewing and Cervero, 2010; Southworth, 2005; Hatamzadeh and Hosseinzadeh, 2019; Hosseinzadeh, 2019; Shamshiripour et al., 2020). Alongside transportation, numerous benefits of promoting walking as an interdisciplinary research area, including environment (Sharifi et al., 2020), economy (Talen and Koschinsky, 2013; Habibian et al., 2015) and public health (Braun et al., 2016), have been focused on in the recent years.

In the past two decades, built environment (BE) has been recognized as a factor that acts as a hidden motivation for individuals to walk more. Therefore, researchers try to identify the influencing environmental factors on walking. According to the definition given by Roof and Oleru (2008), the BE is "a human-made space in which people live, work and recreate on a day-to-day basis" (Roof and Oleru, 2008). To capture the $\mathrm{BE}$, various studies suggest using the three Ds: transportation network design, land use diversity and population density (Cervero and Kockelman, 1997; Ewing and Cervero, 2010; Frank et al., 2005). However, destination accessibility and distance to transit were added to the aforementioned criteria (Ewing and Cervero, 2010).

Although a wide range of studies investigate the relationship between $\mathrm{BE}$ and walking, only a few papers elaborate about how this

${ }^{1}$ Corresponding author: aryan.hosseinzadeh@louisville.edu 
relationship would be changed if various trip purposes were considered separately. Besides, previous studies only consider a single index as representative of each criterion, even though there is a wide range of proposed indices in the literature. Furthermore, most of the studies just consider individuals' residential zones, so the impact of trip attraction zones is unclear. Eventually, most of the objective studies were conducted in small zones in cities of developed countries.

The study possesses five major benefits. First, this research identifies the indices that are effective on various trip purposes. Second, the current study provides an extensive number of indices for each criterion. Therefore, based on the study trip purposes, this study shows which of the investigated indices are more successful in describing walking trip generation. Third, both sides of trip generation have been considered to show which side is more successful in describing walking. Fourth, current research addresses a city of a developing country. Finally, this study has been conducted in the whole city of Rasht, Iran.

In this study, effective factors on the share of walking trips in four trip purposes based on 112 Rasht TAZs have been modeled using various indices, which have been introduced in the literature review. Due to the possibility of different influences of produced and attracted trips, results are reported separately.

The remainder of this paper is organized as follows. The next section provides an overview of the indices of each $\mathrm{BE}$ criterion previously proposed. The third section offers a brief explanation of the method that has been used and provides overviews of the case study and descriptive statistics. The results and conclusion are the fourth and final section of the paper.

\section{Literature Review}

\subsection{BE Criteria}

\section{Design}

Design represents street network characteristics within an area. Quite a few indices have been recommended to encapsulate the effect of transportation network design on walking (Berrigan et al., 2010; Dill, 2004; Gori et al., 2014; Schlossberg, 2006, Behbahani et al., 2019a). Data availability and researchers' preferences are the main determinants of which indices have been used in previous studies (Frank et al., 2010; Frank et al., 2005; Glazier et al., 2012; Krizek, 2003; Behbahani et al., 2019b). What impeded researchers in previous studies to employ all indices is multicollinearity among them. Therefore, studies used one index or employed Principal Component Analysis (PCA) in order to combine several indices and extract one index as their combination (Berrigan et al., 2010). Based on this method, Hatamzadeh et al. (2017) suggested two combined indices that have resulted from PCA. According to their result, two components were extracted that were capable of delineating $71.02 \%$ of variations of all design indices. The first component consists of percentages of fourway intersections and connected node ratio (node connectivity). The second component includes the ratio of minor streets to major streets and street density (link connectivity) (Hatamzadeh et al., 2017). For more detailed literature review of indices see Habibian and Hosseinzadeh (2018). 


\section{Diversity}

Extent and mixture of different land uses in a neighborhood defines diversity (Ewing and Cervero, 2010; Nickkar et al., 2019). Diversity is introduced as the most influential BE criteria in the studies of the last two decades (Maghelal and Capp, 2011). In a longitudinal study, Bentley et al. (2018) certified a positive association between walking and diversity by considering the changes over the years and variation in individuals' walking (Bentley et al., 2018).

Various indices are proposed to measure the diversity of land uses. Table 1 shows the definition and determination method of two common diversity indices in the literature (Habibian and Hosseinzadeh, 2018). Although a large number of studies have implemented the entropy index, Christian et al. (2011) explored the variation of entropy by considering different types and categories and conclude that entropy index could greatly change due to slight modification in land use categorization (Christian et al., 2011). Sugiyama et al. (2019) employed isometric substitution analysis and called the performance of entropy index under question (Sugiyama et al., 2019). Ewing et al. (2015) conclude that high job-population balance in a zone resulted in a 15 percent decrease in Vehicle Mile Traveled (VMT) in that zone (Ewing et al., 2015). Cervero and Duncan (2006), after reconsidering the job population balance, result that the mentioned index is superior comparing other indices such as entropy (Cervero and Duncan, 2006).

Table 1

Formulation of Two Diversity Indices in the Literature

\begin{tabular}{|l|c|c|}
\hline \multicolumn{1}{|c|}{ Index } & Formulation & Source \\
\hline Entropy & $-\frac{\sum_{i=1}^{n} p_{i} \log p_{i}}{\log n}$ & (Frank et al., 2005) \\
& $\begin{array}{l}\text { Pi: Percentage of land use i; } \\
\text { n: Number of land uses; }\end{array}$ & (Ewing et al., 2015) \\
\hline Job-population balance & $1-\left|\frac{\mid 0 b-0.2 \times P o p}{\text { Job }+0.2 \times P o p}\right|$ \\
& $\begin{array}{l}\text { job: Number of jobs in a specific area; } \\
\text { pop: Number of residents in a specific area; }\end{array}$ & \\
\hline
\end{tabular}

\section{Density}

Proportion of the population of a zone to the area of that zone is defined as population density (Frank et al., 2010). This ratio is generally higher at the Central Business District (CBD) of cities in which it is more appropriate to walk (Dobesova and Krivka, 2012).

\section{Destination Accessibility}

Destination accessibility defines as ease of reaching different destinations. It can be measured by distance to various destinations or number of destinations around a location (Ewing and Cervero, 2010). Boakye- Dankwa et al. (2019) show improving access to destinations within a 10 -min walk from home may increase walking in both Australia and Hong Kong case studies (Boakye-Dankwa et al., 2019).

\section{Distance to Transit}

Previous studies use various indices to capture distance to transit criteria. Ewing and Cervero use the shortest distance of an individual's home/workplace to the 
adjacent public transit stop as representative of this criterion (Ewing and Cervero, 2010; Rahimi et al., 2020). The other indices in the literature are total length of the public transit network per area in a zone, average distance between stations in a specific zone and number of stations in a zone (Ewing et al., 2015).

\subsection{Walking and Trip Purposes}

The impact of trip purposes on walking has been investigated in the literature. Yang and Diez-Roux found that walking distance and duration are largely associated with the trip purpose. In this study, seven trip purposes have been discussed (Yang and Diez-Roux, 2012). Frank and Pivo (1994) considered two trip purposes, work and shopping, and show the influencing factors that differ in the resulting models (Frank and Pivo, 1994). Gehrke and Clifton (2017) considered two types of trip purposes in their analysis: walking for transportation and discretionary trips. The results of this study reveal the strong effects of $\mathrm{BE}$ in promoting walking in both mentioned trip purposes (Gehrke and Clifton, 2017). Handy (1992) found that walking for errands is more likely in high-walkable versus low-walkable areas. She also concludes that utilitarian trips (e.g., shopping) are the sources of difference in the share of walking between areas with low- and high-walkability (Handy, 1992). For purposes such as exercise, the differences are not discernable (Handy, 1992). In a recent study in Luxembourg among older adults, Perchoux et al. (2019) conclude that walking distance could be greatly different based on trip purposes (Perchoux et al., 2019). In summary, although there is a wide range of studies that consider trip purposes for walking, none of them consider a TAZ-based analysis to investigate influencing factors.

Although an extensive range of indices is introduced in the literature, there is no mutual consent among the researchers about which of them are most influential. This is because none of the previous studies calculate all the indices in an area to compare the results on encouraging walking. Besides, there is not much knowledge about which of the indices has a greater impact on each trip purpose in TAZ-level analyses. Aggregate studies in the scope of a city could provide an apt ground for decision-makers to take proper action in long-term planning and policymaking.

\section{Data}

\subsection{Area of Study}

The city of Rasht (population approximately 640,000 in 2007) is located in the North of Iran. The urban area in Rasht contains 112 traffic analysis zones (TAZs), which are presented in Figure 1. Unplanned settlements with disordered pathways, low quality and/or condensed houses and weak infrastructure constitute a major part of the spatial structure in the city. With the development of the city and limited space of the bazaar, some commercial activities have moved out from the city center and the traditional bazaar. A poor transit system has made private cars and taxis the most favorable modes of transportation in daily trips (Azimi, 2005; Hatamzadeh et al., 2017). 


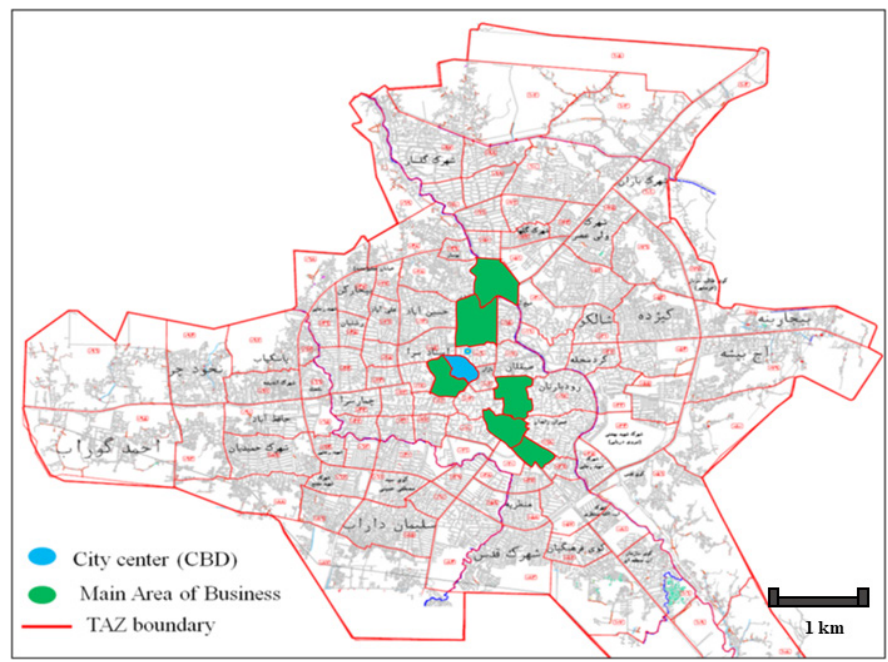

Fig. 1.

Traffic Analysis Zones in Rasht

\subsection{Data Description}

In this study, information from the 2007 Rasht Household Travel Survey (RHTS) is used. As a part of the study, a questionnaire was designed and distributed among more than 5,000 households across 112 TAZs. The aim of the survey was to collect detailed information about every trip taken by all members of each participating household. Each person was asked to fill out a travel diary for a specific day that included the modes of travel, starting and ending time of the trip and the trip purpose. In addition, household information including the number of vehicles owned by type (e.g., car, motorcycle, and bicycle) and household size, as well as individual socio-demographic information such as age, gender and job status were collected (Rasht, 2011).

The data consists of more than 5,000 households, 17,000 individuals and 30,000 trips $(5,501$ work trips, 4,896 educational trips, 2,737 shopping trips and 15,355 return- to-home trips). According to RHTS, $97.25 \%$ of work trips, $99.42 \%$ of educational trips and $95.35 \%$ of shopping trips are homebased, and $62.62 \%$ of Rasht residents have service jobs (Rasht, 2011). Comparing the considered trip purposes, the walk-share related to shopping is higher than others; $47 \%$ of shopping trips are walking although the walk-share in all trips is $31 \%$.

\subsection{Method}

In this study, linear regression analysis is used to model the influencing factors on the share of walking trips. The share of walking trips in a zone is considered a dependent variable, and socio-demographic characteristics and built environment criteria are used as independent variables. Thus, the model can be represented in equation 1 :

$Y_{i}=\beta_{1}+\beta_{2} x_{2 i}+\beta_{3} x_{3 i}+\ldots+u_{i}$

Given a data set of $n$ TAZs, a linear regression model assumes that the relationship between 
the share of walking $Y_{i}$ and each of the independent variables is linear (equation 1 ).

This relationship is modeled through an error term $u_{i}$, an unobserved random variable that adds noise to equation 1 .

In developing equation 1 , it has assumed the error term has population mean of zero (equation 2), no serial correlation (equation 3), homoscedasticity of the error term (equation 4 ), zero covariance between $u_{i}$ and each $x_{i}$ variables (equation 5), no specification bias and no exact collinearity between the $x$ variables. The validity of assumptions has been checked to ensure no assumptions violations exist.

$E\left(u_{i} \mid X_{2 i}, X_{3 i}\right)=0$ for each $i$

$\operatorname{Cov}\left(u_{i}, u_{j}\right)=0$

$\operatorname{Var}\left(\mathrm{u}_{\mathrm{i}}\right)=\sigma^{2}$

$\operatorname{Cov}\left(u_{i}, X_{2 i}\right)=\operatorname{Cov}\left(u_{i}, X_{3 i}\right)=0$
The goodness of fit and adjusted goodness of fit for the model resulted from equation 6 and equation 7.

$$
\begin{aligned}
& R^{2}=\frac{E S S}{T S S}=\frac{\widehat{\beta_{2}} \sum y_{i} x_{2 i}+\widehat{\beta_{3}} \sum y_{i} x_{3 i}+}{\sum y_{i}^{2}} \\
& \overline{R^{2}}=1-\frac{\sum \widehat{u}_{i}^{2} /(n-k)}{\sum y_{i}^{2} /(n-1)}
\end{aligned}
$$

\subsection{Analysis}

To capture the variation resulted in trip generation, the walk-shares of produced and attracted trips are considered. In addition, walking trips are considered for four purposes of trips (i.e., work, education, shopping and return-to-home). Since the length of the trip is not reported in the data, the distance between centroids of the produced and attracted TAZs is used as trip length. The variables of this study consist of walk-share as a dependent variable, while socio-economic variables and indices related to each of the $\mathrm{BE}$ criteria are treated as independent variables. Descriptive statistics, number and percentage in each purpose of the trip are presented in Table 2.

Table 2

Number and Percentage of All Trips and Walking Trips in Each Trip Purpose

\begin{tabular}{|l|l|l|l|l|l|}
\hline \multicolumn{2}{|l|}{} & Work & Education & Shopping & Return-to-home \\
\hline Number of all trips & 5501 & 4896 & 2737 & 15355 \\
\hline Number of walking trips & 892 & 1805 & 1295 & 4901 \\
\hline $\begin{array}{l}\text { Walking share (produced and attracted) } \\
\text { (Percent) }\end{array}$ & 16.2 & 36.9 & 47.3 & 31.9 \\
\hline \multirow{2}{*}{ Produced } & Average & 16.1 & 33 & 41.1 & 34.1 \\
\cline { 2 - 6 } & Standard deviation & 10.4 & 16.8 & 21.6 & 16.3 \\
\hline \multirow{2}{*}{ Attracted } & Average & 18 & 37.5 & 62.7 & 28.7 \\
\cline { 2 - 6 } & Standard deviation & 13.3 & 24.4 & 31.4 & 11 \\
\hline
\end{tabular}

Socio-demographic variables within each TAZ, including the average age, household size, bike ownership, motorcycle ownership and car ownership, are calculated. Descriptive statistics of the socio- demographic variables are presented in the first part of Table 3.

Design indices are calculated based on the GIS database of the transportation network of Rasht, which has been collected as a part of RHTS. GIS software has been used to 
calculate indices in 112 TAZs of Rasht. The first part of Table 3 shows descriptive statistics of the design indices.

Land use diversity variables are calculated based on the Rasht land use database, which was gathered in RHTS. The second part of
Table 3 shows the descriptive statistics of calculated diversity variables.

The population density that has been calculated in each TAZ of Rasht is represented in the third part of Table 3.

Table 3

Zone-based Independent Variables Descriptive Statistics

\begin{tabular}{|c|c|c|c|c|c|c|}
\hline & & Average & S.D. & Min & Max & \\
\hline \multicolumn{7}{|c|}{ Part 1-Socio-economic Variables } \\
\hline $1-1$ & Age average & 30.01 & 2.83 & 22.33 & 40.25 & - \\
\hline $1-2$ & Household size & 3.51 & 0.19 & 3 & 4.33 & - \\
\hline $1-3$ & Average bike ownership & 0.66 & 0.12 & 0.375 & 1.008 & - \\
\hline $1-4$ & Average motor ownership & 0.12 & 0.07 & 0 & 0.43 & - \\
\hline $1-5$ & Average car ownership & 0.57 & 0.24 & 0.26 & 0.95 & - \\
\hline \multicolumn{7}{|c|}{ Part 2-Connectivity Indices } \\
\hline $2-1$ & Intersection density & 244.5 & 134.32 & 1.24 & 656.29 & $1 / \mathrm{km}^{2}$ \\
\hline $2-2$ & Percentage of 4-way intersections & 14.1 & 6.44 & 0 & 38.9 & - \\
\hline $2-3$ & Cal-de-sac density & 146.11 & 91.01 & 0 & 407.8 & $1 / \mathrm{km}^{2}$ \\
\hline $2-4$ & Number of cal-de-sac & 75 & 62.6 & 0 & 363 & - \\
\hline $2-5$ & Number of 3-way & 104 & 80.6 & 3 & 449 & - \\
\hline $2-6$ & Number of 4-way & 15 & 11.96 & 0 & 69 & - \\
\hline $2-7$ & Ratio of minor streets to major streets & 11.57 & 25.63 & 0 & 187.56 & - \\
\hline $2-8$ & Street density & 0.017 & 0.0084 & 0.004 & 0.035 & $\mathrm{~m} / \mathrm{km}^{2}$ \\
\hline $2-9$ & 3-way intersection density & 210.88 & 116.92 & 1.24 & 535 & $1 / \mathrm{km}^{2}$ \\
\hline $2-10$ & 4-way intersection density & 33.62 & 23.98 & 0 & 121.2 & $1 / \mathrm{km}^{2}$ \\
\hline $2-11$ & Connected node ratio & 0.62 & 0.1 & 0.4 & 1 & - \\
\hline $2-12$ & Ratio of links to nodes & 1.86 & 0.2 & 1.55 & 2.25 & $1 / \mathrm{m}$ \\
\hline $2-13$ & Gamma index & 0.39 & 0.05 & 0.33 & 0.63 & - \\
\hline $2-14$ & Alpha index & 0.09 & 0.059 & 0.01 & 0.36 & - \\
\hline $2-15$ & Percentage of 3-way intersections & 85.9 & 10.32 & 61.09 & 100 & - \\
\hline $2-16$ & Number of major 3-way intersections & 7.61 & 7.48 & 0 & 49 & - \\
\hline $2-17$ & Number of major 4-way intersections & 1.34 & 1.67 & 0 & 11 & - \\
\hline $2-18$ & Ratio of cal-de-sac to nodes & 37.01 & 9.22 & 0 & 60 & - \\
\hline $2-19$ & Major street density & 3653.4 & 2967.5 & 0 & 16149.4 & $\mathrm{~m} / \mathrm{km}^{2}$ \\
\hline $2-20$ & Minor street density & 21648 & 8836.3 & 610 & 36898 & $\mathrm{~m} / \mathrm{km}^{2}$ \\
\hline $2-21$ & Average link length & 54.37 & 24.95 & 27.2 & 227.46 & $\mathrm{~m}$ \\
\hline $2-22$ & Node connectivity & 0.6 & 0.13 & 0.32 & 1.34 & - \\
\hline $2-23$ & Link connectivity & 18.3 & 26.20 & 0.03 & 166.5 & - \\
\hline \multicolumn{7}{|c|}{ Part3-Diversity Indices } \\
\hline 3-1 & Entropy index & 0.33 & 0.19 & 0 & 0.83 & - \\
\hline $3-2$ & HHI & 0.72 & 0.18 & 0.29 & 1 & - \\
\hline $3-3$ & MXI & 35.8 & 11.3 & 1.64 & 50 & - \\
\hline $3-4$ & Job-population balance & 0.56 & 0.29 & 0 & 1 & - \\
\hline \multicolumn{7}{|c|}{ Part4-Density Index } \\
\hline $4-1$ & Population density & 10100 & 6600 & 0 & 28700 & $1 / \mathrm{km}^{2}$ \\
\hline \multicolumn{7}{|c|}{ Part5-Destination Accessibility Indices } \\
\hline 5-1 & Areal distance to CBD & 2629 & 1712 & 0 & 10626 & $\mathrm{~m}$ \\
\hline $5-2$ & Network distance to CBD & 3334 & 2318 & 0 & 14782 & $\mathrm{~m}$ \\
\hline
\end{tabular}




\section{Results and Discussion}

\section{Walking Trip Production}

The first part of Table 4 shows percentages of walking in produced trips for considered trip purposes in Rasht, which reports effective variables and significance levels. In Table
4, population density positively affects the walk-share among all trip purposes. A wide range of studies found the positive impact of higher population density on walking (Frank et al., 2010; Frank et al., 2005; Hong et al., 2014). Population density is also important in the produced return- to-home trips.

\section{Table 4}

Produced and Attracted Trip Models for Each Trip Purpose

\begin{tabular}{|c|c|c|c|c|c|}
\hline & & Work & Educational & Shopping & Return-to-Home \\
\hline \multirow{7}{*}{ 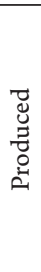 } & Constant & $0.12^{* * *}$ & $0.259^{* *}$ & $0.215^{* * *}$ & $0.101^{* * *}$ \\
\hline & Population density & $0.000293^{* *}$ & $0.000622^{* *}$ & $0.0001093^{* * *}$ & $0.000288^{*}$ \\
\hline & Link connectivity & - & $0.42^{* *}$ & $0.66^{* * *}$ & - \\
\hline & Job-population balance & - & - & $0.129^{* *}$ & $0.362^{* * *}$ \\
\hline & Ratio of minor to major streets & $0.00066^{* * *}$ & - & - & - \\
\hline & $\mathrm{R}^{2}$ & 0.066 & 0.173 & 0.396 & 0.479 \\
\hline & Adj- $R^{2}$ & 0.049 & 0.158 & 0.380 & 0.470 \\
\hline \multirow{6}{*}{ 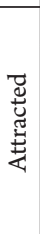 } & Constant & $0.054^{* * *}$ & $0.232^{* * *}$ & $0.228^{* * *}$ & $0.255^{* * *}$ \\
\hline & Population density & $0.000293^{* *}$ & - & $0.000744^{* * *}$ & $0.000699^{*}$ \\
\hline & Job-population balance & $0.218^{* * *}$ & $0.387^{* * *}$ & $0.548^{* *}$ & \\
\hline & Average length of links & - & $-0.00147^{*}$ & - & $-0.00085^{* *}$ \\
\hline & $\mathrm{R}^{2}$ & 0.234 & 0.287 & 0.338 & 0.262 \\
\hline & Adj-R2 & 0.227 & 0.273 & 0.326 & 0.249 \\
\hline
\end{tabular}

Note: ${ }^{* *},{ }^{* *}$ and ${ }^{*}$ denote a $99 \%, 95 \%$ or $90 \%$ level of significance, respectively.

Results also show the importance of design indices. Link connectivity, as a design index, is positively effective in shopping and educational trip models. Higher link connectivity means a denser street network, as well as a higher ratio of minor to major streets. Since shopping opportunities are more frequent in minor streets, higher values of this index improve the shopping chance from passing individuals while walking. Thus, a denser street network in minor streets, which is a significant part of link connectivity, results in denser shopping opportunities. The compound design index, link connectivity, also increases educational walking trips (Educational trips consist of students between 7 to 18 years old who go to school and more than 18 years old who attend the university). In major streets, cars with high speeds and wide streets make crossing difficult for students (Hong et al., 2014). In this case, students are more vulnerable and less experienced compared to adults. Therefore, the "ratio of minor streets to major streets" can represent the situation properly. Previous studies in the literature highlight safety concerns of parents in their children's educational trips (Boarnet et al., 2005; Buliung et al., 2017; Kerr et al., 2006; Karimpour et al., 2019).

In work trips, a denser street network secures more diverse routes, which provides the possibility of choosing a more direct or more attractive route. Increasing the ratio of minor streets to major streets enhances 
safety and, thus, encourages individuals to do more walking in their work trips. Since cars usually are driven at lower speed on minor streets, citizens are more likely to walk along them (Jacobsen, 2015). As illustrated in Table 4, the larger ratio of minor streets to major streets results in a higher percentage of walking in work trips. In the produced trips model, BE factors have been more successful in describing walking in return-to-home and shopping trips.

\subsection{Walking Trip Attraction}

The second part of Table 4 shows the influencing factors on walking trip attraction models. In this study, all the diversity indices have been entered in the model to determine which ones are more successful in describing walking. Results show the positive impact of diversity indices in work, educational, and shopping trips in the destination zone. The job-population balance, as a diversity index, means more balance between residents and available jobs in a zone. For instance, in work trips, residential land uses adjacent to zones with existing job opportunities increases the possibility of working near the residential location. As a result, more walking to work takes place due to the short distance between workplace and home (Ewing et al., 2015). Although each of the diversity indices mentioned in Part 3 of Table 3 were tested in the model, the job-population balance was the only one found to be significant. This result is different from most previous studies, in which the entropy index is considered as a proxy of diversity (Badland et al., 2009; Frank et al., 2010; Frank et al., 2005; Talen and Koschinsky, 2013). However, another study casts doubt about the sufficiency of the entropy index because it assumes equal weight for all land uses (Christian et al., 2011).
The average length of streets in the street network shows the distance between nodes in the network, which has been found to be influential in educational and return-to-home trips. Negative values of the coefficients mean individuals do not have a tendency to reach destinations by taking long roads. In fact, shorter roads indicate the possibility to choose a more efficient route to reach a destination and prevent people from walking along lengthy and boring streets. Additionally, drivers must reduce their speed before reaching intersections on short roads. It seems that the index is more influential in educational attracted trips because students are less experienced in interacting with cars, so streets with lower traveling speed are more suitable for students to walk (Kerr et al., 2006).

The impact of population density on job trips is the lowest among all trip purposes, which is aligned with findings of Ramezani et al. (2018) (Ramezani et al., 2018). Moreover, in the modeling of work trips, attraction model is more successful than produced model. This finding is in accordance with the recent study that highlights the importance of workplace surroundings (Adams et al., 2016).

\section{Conclusion}

In this study, effective indices on walking trip generation are investigated. Five different factors from all those calculated were found to be significant in all eight models.

Density and design demonstrated a positive effect on walking to work, educational- and shopping-produced and return-to-home attracted trips. These findings reveal that density and design were more important around peoples' residences. Comparing all the significant variables in the walk-share 
of trip generations, the population density index was found to be influential in seven out of eight models. Design indices (i.e., average length of links, ratio of minor roads to major roads and link connectivity) have been significant in five out of the eight models, four of which are in individuals' residential TAZs. This finding is aligned with the previous studies that consider these criteria in a buffer around the homes of the participants in the surveys (Cao, 2014; Frank et al., 2005; Lamíquiz and López-Domínguez, 2015; Talen and Koschinsky, 2013)

Job-population balance, a diversity index, has been found significant in five out of the eight total models. Diversity was found to be important in the destination, not including the individuals' places of residence. This is in contrast with studies in the literature that assumed that diversity was important around peoples' homes (Frank et al., 2005; Talen and Koschinsky, 2013). In addition, among all diversity indices, the job-population balance was found to be significant in the city of Rasht, while most parts of the literature suggest using the entropy index as a proxy of diversity (Talen and Koschinsky, 2013).

According to the reported goodness of fit in the walk-share trip generation, shopping and return-to-home trips had the highest goodness of fit. In work and educational trips, people need to be at their destinations at a certain time. Faster modes of transportation are preferred and $\mathrm{BE}$ characteristics may not affect them. However, in shopping and return-to-home trips, people have more time, so it is more probable that environmental characteristics have an impact on walking.
Some limitations are important to point out. First, the major way of commuting is reported by individuals, rather than the details of their trip chains. Furthermore, there is information about individuals' production and attraction TAZs, not the exact routes of their trips. If the exact route was given, all the TAZs involved in the trip could be included in the analysis. Although a wide range of indices are calculated, there are some others that could help to reach more profound results: density of bus stops, pedestrian catchment area, block density and pedestrian route directness. In addition, various path attributes such as slope, adjacent traffic volumes and presence/width of sidewalks have not been calculated in this study, which could be helpful in reflecting on some key factors influencing walking for various trip purposes.

\section{References}

Adams, E.J.; Bull, F.C.; Foster, C.E. 2016. Are perceptions of the environment in the workplace 'neighbourhood'associated with commuter walking?, Journal of Transport \& Health 3(4): 479-484.

Azimi, N. 2005. Restructuring Urban Morphology, a Case Study of Rasht in Iran, Geographical Research 53: 13-25.

Behbahani, H.; Nazari, S.; Kang, M.J.; Litman, T. 2019a. A conceptual framework to formulate transportation network design problem considering social equity criteria, Transportation research part A: policy and practice 125: 171-183.

Behbahani, H.; Nazari, S.; Partovifar, H.; Kang, M.J. 2019b. Designing a Road Network Using John Rawls's Social Justice Approach, Journal of Urban Planning and Development 145(2): 05019002. 
Behbahani, H.; Nazari, S.; Partovifar, H.; Kang, M.J. 2019b. Designing a Road Network Using John Rawls's Social Justice Approach. Journal of Urban Planning and Development, 145(2), p.05019002.

Bentley, R.; Blakely, T.; Kavanagh, A.; Aitken, Z.; King, T.; McElwee, P.; Giles-Corti, B.; Turrell, G. 2018. A longitudinal study examining changes in street connectivity, land use, and density of dwellings and walking for transport in Brisbane, Australia, Environmental Health Perspectives 126(5): 057003.

Berrigan, D.; Pickle, L.W.; Dill, J. 2010. Associations between street connectivity and active transportation, International journal of health geographics 9(1): 20.

Boakye-Dankwa, E.; Nathan, A.; Barnett, A.; Busija, L.; Lee, R.S.; Pachana, N.; Turrell, G.; Cerin, E. 2019. Walking behaviour and patterns of perceived access to neighbourhood destinations in older adults from a low-density (Brisbane, Australia) and an ultra-dense city (Hong Kong, China), Cities 84: 23-33.

Boarnet, M.G.; Day, K.; Anderson, C.; McMillan, T.; Alfonzo, M. 2005. California's Safe Routes to School program: impacts on walking, bicycling, and pedestrian safety, Journal of the American Planning Association 71: 301-317.

Braun, L.M.; Rodriguez, D.A.; Song, Y.; Meyer, K.A.; Lewis, C.E.; Reis, J.P.; Gordon-Larsen, P. 2016. Changes in walking, body mass index, and cardiometabolic risk factors following residential relocation: Longitudinal results from the CARDIA study, Journal of Transport \& Health 3(4): 426-439.

Buliung, R.N.; Larsen, K.; Faulkner, G.; Ross, T. 2017. Children's independent mobility in the City of Toronto, Canada, Travel Behaviour and Society 9: 58-69.

Cao, J. 2014. Residential self-selection in the relationships between the built environment and travel behavior: Introduction to the special issue, Journal of Transport and Land Use 7(3): 1-3.
Cervero, R.; Duncan, M. 2006. Which Reduces Vehicle Travel More: Jobs-Housing Balance or Retail-Housing Mixing?, Journal of the American planning association 72: 475-490.

Cervero, R.; Kockelman, K. 1997. Travel demand and the 3Ds: density, diversity, and design, Transportation Research Part D: Transport and Environment 2(3): 199-219.

Christian, H.E.; Bull, F.C.; Middleton, N.J.; Knuiman, M.W.; Divitini, M.L.; Hooper, P.; Amarasinghe, A.; Giles-Corti, B. 2011. How important is the land use mix measure in understanding walking behaviour? Results from the RESIDE study, International Journal of Behavioral Nutrition and Physical Activity 8(1): 55.

Dill,J. 2004. Measuring network connectivity for bicycling and walking, In Proceedings of the 83rd Annual Meeting of the Transportation Research Board, Washington, DC, 11-15.

Dobesova, Z.; Krivka, T. 2012. Walkability index in the urban planning: A case study in Olomouc city. Advances in spatial planning, 179-197.

Ewing, R.; Cervero, R. 2010. Travel and the built environment: a meta-analysis, Journal of the American Planning Association 76: 265-294.

Ewing, R.; Tian, G.; Goates, J.P.; Zhang, M.; Greenwald, M.J.; Joyce, A.; Kircher, J.; Greene, W. 2015. Varying influences of the built environment on household travel in 15 diverse regions of the United States, Urban Studies 52(13): 2330-2348.

Frank, L.D.; Pivo, G. 1994. Impacts of mixed use and density on utilization of three modes of travel: singleoccupant vehicle, transit, and walking, Transportation research record 1466: 44-52.

Frank, L.D.; Sallis, J.F.; Saelens, B.E.; Leary, L.; Cain, K.; Conway, T.L.; Hess, P.M. 2010. The development of a walkability index: application to the Neighborhood Quality of Life Study, British journal of sports medicine 44(13): 924-933. 
Frank, L.D.; Schmid, T.L.; Sallis, J.F.; Chapman, J.; Saelens, B.E. 2005. Linking objectively measured physical activity with objectively measured urban form: findings from SMARTRAQ, American journal of preventive medicine 28(2): 117-125.

Gehrke, S.R.; Clifton, K.J. 2017. A pathway linking smart growth neighborhoods to home-based pedestrian travel, Travel Behaviour and Society 7: 52-62.

Glazier, R.H.; Weyman, J.T.; Creatore, M.I.; Gozdyra, P.; Moineddin, R.; Matheson, F.I.; Booth, G.L. 2012. Development and validation of an urban walkability index for Toronto, Canada. Toronto Community Health Profiles Partnership, 1-21.

Gori, S.; Nigro, M.; Petrelli, M. 2014. Walkability indicators for pedestrian-friendly design, Transportation Research Record 2464(1): 38-45.

Habibian, M.; Avaz, Z.; Hosseinzadeh, A. 2015. Sociological Study of Influence of Citizen's Traffic Ethics on Driving Violations: Case Study of Tehran, Iran, In Proceedings of the $94^{\text {th }}$ Annual Meeting of the Transportation Research Board, Washington, DC, No. 15-6029.

Habibian, M.; Hosseinzadeh, A. 2018. Walkability index across trip purposes, Sustainable cities and society 42: 216-225.

Handy, S.L. 1992. Regional versus local accessibility: neo-traditional development and its implications for non-work travel, Built Environment 1978: 253-267.

Hatamzadeh, Y.; Habibian, M.; Khodaii, A. 2017. Walking and jobs: A comparative analysis to explore factors influencing flexible and fixed schedule workers, a case study of Rasht, Iran, Sustainable cities and society 31: 74-82.
Hatamzadeh, Y.; Hosseinzadeh, A. 2019. Toward a deeper understanding of elderly walking mode choice behavior: An analysis across genders in a case study of Iran, In Proceedings of the 15th World Conference on Transport Research.

Hong, J.; Shen, Q.; Zhang, L. 2014. How do builtenvironment factors affect travel behavior? A spatial analysis at different geographic scales, Transportation 41(3): 419-440.

Hosseinzadeh, A. 2019. Built Environment and Walking: Short vs. Long Walking Trips. arXiv preprint arXiv:2001.00640.

Jacobsen, P.L. 2015. Safety in numbers: more walkers and bicyclists, safer walking and bicycling, Injury prevention 21(4): 271-275.

Karimpour, A.; Ariannezhad, A.; Wu, Y.J. 2019. Hybrid data-driven approach for truck travel time imputation, IET Intelligent Transport Systems 13(10): 1518-1524.

Kerr, J.; Rosenberg, D.; Sallis, J.F.; Saelens, B.E.; Frank, L.D.; Conway, T.L. 2006. Active commuting to school: associations with environment and parental concerns, Medicine \& Science in Sports \& Exercise 38(4): 787-793.

Krizek, K.J. 2003. Operationalizing neighborhood accessibility for land use-travel behavior research and regional modeling, Journal of Planning Education and Research 22(3): 270-287.

Lamíquiz, P.J.; López-Domínguez, J. 2015. Effects of built environment on walking at the neighbourhood scale. A new role for street networks by modelling their configurational accessibility?, Transportation Research Part A: Policy and Practice 74: 148-163. 
Maghelal, P.K.; Capp, C.J. 2011. Walkability: A Review of Existing Pedestrian Indices, Journal of the Urban \& Regional Information Systems Association 23(2): 15-19.

Nickkar, A.; Banerjee, S.; Chavis, C.; Bhuyan, I.A.; Barnes, P. 2019. A spatial-temporal gender and land use analysis of bikeshare ridership: The case study of Baltimore City, City, Culture and Society 18: 100291.

Perchoux, C.; Brondeel, R.; Wasfi, R.; Klein, O.; Caruso, G.; Vallée, J.; Klein, S.; Thierry, B.; Dijst, M.; Chaix, B.; Kestens, Y. 2019. Walking, trip purpose, and exposure to multiple environments: a case study of older adults in Luxembourg, Journal of Transport \& Health 13: 170-184.

Rahimi, A.; Azimi, G.; Jin, X. 2020. Examining human attitudes toward shared mobility options and autonomous vehicles, Transportation Research Part F: Traffic Psychology and Behaviour 72: 133-154.

Ramezani, S.; Pizzo, B.; Deakin, E. 2018. An integrated assessment of factors affecting modal choice: towards a better understanding of the causal effects of built environment, Transportation 45(5): 1351-1387.

Rasht. 2011. Rasht comprehensive transportation planning study. Final report (final edition), Municipality of Rasht (Andishkar consulting engineers).

Roof, K.; Oleru, N. 2008. Public health: Seattle and King County's push for the built environment, Journal of environmental health 71(1): 24-27.
Schlossberg, M. 2006. From TIGER to audit instruments: Measuring neighborhood walkability with street data based on geographic information systems, Transportation Research Record 1982(1): 48-56.

Shamshiripour, A.; Rahimi, E.; Shabanpour, R.; Mohammadian, A.K. 2020. Dynamics of travelers' modality style in the presence of mobility-on-demand services, Transportation Research Part C: Emerging Technologies 117: 102668.

Sharifi, M.S.; Song, Z.; Esfahani, H.N.; Christensen, K. 2020. Exploring heterogeneous pedestrian stream characteristics at walking facilities with different angle intersections, Physica A: Statistical Mechanics and its Applications 540: 123112.

Southworth, M. 2005. Designing the walkable city, Journal of urban planning and development 131(4): 246-257.

Sugiyama, T.; Rachele, J.N.; Gunn, L.D.; Burton, N.W.; Brown, W.J.; Turrell, G. 2019. Land use proportion and walking: Application of isometric substitution analysis, Health \& place 57: 352-357.

Talen, E.; Koschinsky, J. 2013. The walkable neighborhood: A literature review, International Journal of Sustainable Land Use and Urban Planning 1(1): 42-63.

Yang, Y.; Diez-Roux, A.V. 2012. Walking distance by trip purpose and population subgroups, American journal of preventive medicine 43(1): 11-19. 